\title{
Effects of three aging methods on the Longissimus lumborum muscle from Holstein-Friesian steers")
}

\author{
HATICE AHU KAHRAMAN, ÜMIT GÜRBÜZ**** \\ Mehmet Akif Ersoy University, Faculty of Veterinary Medicine, Department of Food Hygiene and Technology, \\ 15030, Burdur/Turkey \\ *Selçuk University, Faculty of Veterinary Medicine, Department of Food Hygiene and Technology, 42003, Konya/Turkey \\ ${ }^{* *}$ Kyrgyz-Turkish Manas University, Faculty of Veterinary Medicine, Department of Food Hygiene and Technology, \\ 720044, Bishkek/Kyrgyzstan
}

Kahraman H. A., Gürbüz Ü.

\section{Effects of three aging methods on the Longissimus Iumborum muscle from Holstein-Friesian steers}

\section{Summary}

The aim of this study was to investigate the effects of three aging processes (traditional dry aging, wet aging in vacuum shrink pack and dry aging in a highly moisture-permeable bag) in five aging times $(0,7,14,21,28$ days) for their effects on physical, chemical, microbial, histological, textural and sensory properties of beef Longissimus lumborum muscle from Holstein-Friesian steers. Longissimus lumborum muscles were aged dry (D), in a dry-aging bag (B) and a vacuum shrink pack (V) for 28 days at $0.5^{\circ} \mathrm{C} \pm 0.5$ with $80 \%$ humidity. An increase was observed in pH and TBARS values of all samples. All methods caused a decrease in the WBSF value. The decrease of WBSF was rapid until the $14^{\text {th }}$ day. V samples had lower WBSF values in comparison with others. While the $L$ *and $a^{*}$ values were similar on the $28^{\text {th }}$ day in all groups, $b$ * values were different $(p<0.05)$. There were no significant effects of aging treatment on the sarcomere length on the $28^{\text {th }}$ day $(p>0.05)$. An increase was also observed in the numbers of the total viable count, total psychrophilic bacteria, Enterobacteriaceae, lactic acid bacteria and yeast-mold in all groups. B aging may have a positive effect on safety, quality, yield and shelf stability of aged-beef. $V$ aging significantly improves both textural and sensory characteristics of meat. The most positive effect on flavor, juiciness, tenderness and overall like were observed in the $V$ aged treatment on the $14^{\text {th }}$ day of aging. The use of the vacuum shrink pack is considered to be an alternative packing material in the wet aging method to improve the physicochemical and sensory quality of beef.

Keywords: beef, dry aging, dry aging bag, meat quality, vacuum shrink

Natural enzymatic processes which enable improving meat palatability attributes such as flavor, juiciness or tenderness occur during post-mortem aging of beef $(12,17-19,21)$. Meat aging is a process that improves the tenderness and taste of the carcass or its parts at refrigerated temperatures (16). Several studies have reported that the aging process provides desirable flavor $(5,37)$. In addition, many studies have also mentioned that meat tenderness is one of the most priceless characteristics according to consumers $(3,15,20)$. In general, there are two methods of meat aging: wet and dry. In the wet aging, meat is vacuum packed into a moisture-barrier bag and stored under refrigeration (34), while no packaging is used and storing conditions are controlled in the dry aging (8). A higher yield loss

\footnotetext{
1) This article is summarized from the Ph.D thesis entitled Application of Dif-
} ferent Aging Methods to Boned and Boneless Cattle Striploins (M. Longissimus Lumborum) and Determination of the Quality Features by H. A. Kahraman. The authors thank Prof. Dr. Emrah Sur for his help on the histological analysis and Tub-ExApS, Denmark for their involvement with this study. through moisture loss in dry aging process makes these products about $15-20 \%$ more expensive. Therefore, an alternative method is necessary to present these products to consumers with minimum weight loss. Recently, dry aging in a highly moisture permeable bag, which is another method of dry aging, has been widely used. In this method, meat is packed in a highly moisture permeable bag and stored under controlled conditions such as the traditional dry aging method (1). The developments in packaging and vacuum techniques have provided a new vision to meat aging. As the packaging method is improved, it becomes a safe way of storing, shipping and maintaining shelf stability of aged-beef due to its commercial advantages.

Therefore, the purpose of this study was to investigate the effects of three aging processes (traditional dry aging, wet aging in a vacuum shrink pack and dry aging in a highly moisture-permeable bag) in five aging times $(0,7,14,21,28$ days) for their effects on 
physical, chemical, microbial, histological, textural and sensory properties of beef Longissimus lumborum muscle from Holstein-Friesian steers.

\section{Material and methods}

Animals and treatments. Six 22-24 month-old HolsteinFriesian breed steers were used for this study. All animals were slaughtered humanely and dressed according to standard procedures of the commercial slaughtering plant. The average carcass weight was $350 \mathrm{~kg}$. On $24 \mathrm{~h}$ post-mortem, the Longissimus lumborum muscle (LL), from the $12^{\text {th }}$ rib, was cut out from both sides of each carcass and subcutaneous fat was not removed. Twelve LL muscles $(\mathrm{n}=12)$ were shipped under refrigeration to the University of Selçuk, Faculty of Veterinary Medicine, Meat Products Research, Practice, and Development Center.

Aging and sampling. Twelve LL muscles were divided into three groups. Each LL muscle was paired with five pieces equally according to the aging times $(0,7,14,21$, 28 days). Three different procedures $(n=20 /$ per treatment $)$ were applied to 60 loin sections $(\mathrm{n}=60)$ in total. Each side (right or left) of LL muscles from the same carcass was used for different aging procedures. All loin sections were aged as discussed below. [1] Dry aging in bag application of boneless meat (B). Samples were packed in dry aging bags (Tublin ${ }^{\circledR} 10$, TUB-EX ApS, Denmark). The bags were made of a polyamide mix and were in $200 \times 300 \times 0.05 \mathrm{~mm}$ size with water vapor transmission rate $5000 \mathrm{~g} / 50 \mu / \mathrm{m}^{2} / 24 \mathrm{~h}$ at $38^{\circ} \mathrm{C}$ and $50 \%$ relative humidity. [2] Wet aging (heat-shrink vacuum bag) application of boneless meat. Samples were packed in vacuum shrink packs (V). The vacuum shrink bags (Cryovac ${ }^{\circledR}$ BB3050U, Sealed Air Corporation, USA) were of a $250 \times 300 \times 0.04 \mathrm{~mm}$ size, the permeability of water vapor was $7 \mathrm{~g} / \mathrm{m}^{2}, 24 \mathrm{~h}$, bar at $38^{\circ} \mathrm{C}, 90 \%$ relative humidity. Vacuum shrink packs were immersed in a water bath at $85^{\circ} \mathrm{C}$ for $2 \mathrm{~s}$. All packs were vacuumed using a double-chamber vacuum packager (model C500; Multivac Inc., Kansas City, MO). [3] Traditional dry aging application (D) of bone-in meat. The meat samples were stored on stainless steel gratings at $0.5 \pm 0.5^{\circ} \mathrm{C}, 85 \% \mathrm{RH}, 0.2-0.5 \mathrm{~m} / \mathrm{s}$ in a commercial meat plant chiller. The temperature and the humidity of the chillers were monitored using a data logger (Testo $174 \mathrm{H}$, Germany). Samples were turned over and rotated every day to minimize location effects. Following storage, the weight of the samples was measured and they were analyzed on the 0 (the initial day), $7,14,21$, and 28 days of the aging process.

Physicochemical analyses. The $\mathrm{pH}$ value was measured using a penetration $\mathrm{pH}$ meter (Testo 205, Lenzkirch). It was calibrated at $\mathrm{pH} 7.01$ and 4.01 with standard buffers stored at room temperature. The $\mathrm{a}_{\mathrm{w}}$ value was measured using a portative hygrometer (Novasina AG, Lachen). The instrument was calibrated with three water activity standards, namely $33 \%$ $\left(\mathrm{a}_{\mathrm{w}}=0.332\right), 58 \%\left(\mathrm{a}_{\mathrm{w}}=0.586\right)$ and $84 \%\left(\mathrm{a}_{\mathrm{w}}=0.845\right)$. Moisture content was measured using a moisture analyzer (AND MX-500, AD Company). The moisture analyzer's weighing sensor was calibrated using special mass (AX-MX-41) and drying temperature was calibrated using a temperature calibrator (AX-MX-43). Samples were allowed to bloom for $30 \mathrm{~min}$ at a temperature of $3-4^{\circ} \mathrm{C}$ before making initial color measurements. The surface color (3) of samples was measured using a colorimeter (CR-400, Minolta Company, Osaka, Japan) with an 8-mm-diameter measuring aperture, illumi- nant D65, $2^{\circ}$ standard observers According to. The colorimeter was calibrated using a standard white tile $\left(\mathrm{L}^{*}=97.65\right.$, $\left.\mathrm{a}^{*}=-0.10, \mathrm{~b}^{*}=-0.14\right)$ before measurement. The total weight loss (\%) of the samples was calculated as in the following: (sample weight before aging - sample weight after aging)/ sample weight before aging $\times 100 \%$. All measurements were made in the laboratory at the room temperature $\left(20^{\circ} \mathrm{C}\right)$.

Lipid oxidation was determined by measuring thiobarbituric acid reactive substances (TBARS) values according to the method described by researchers (36). Ten-gram samples were added to $49 \mathrm{ml}$ of distilled water at $50^{\circ} \mathrm{C}$ and $1 \mathrm{ml}$ reactive of sulfanilamide, and then homogenized using a tissue homogenizer (WiseTis Homogenizer, HG-15D, Daihan Scientific) for $30 \mathrm{~s}$. After that, $48 \mathrm{ml}$ of distilled water at $50^{\circ} \mathrm{C}, 2 \mathrm{ml} 1: 2 \mathrm{HCl}$ solution, glass boiling bead and silicon antifoaming agent (Merck 1.107743) were added. Samples were placed in a distillation unit. $5 \mathrm{ml}$ of distillate and $5 \mathrm{ml}$ of $0.02 \mathrm{M} 2$-thiobarbituric acid were added into the tubes, then heated in a water bath at $95^{\circ} \mathrm{C}$ for $35 \mathrm{~min}$ and cooled in iced water. The absorbance of the samples was measured at $530 \mathrm{~nm}$ using a spectrophotometer (Shimadzu UV 1601 Visible, Tokyo, Japan) against the blank (5 $\mathrm{ml}$ of distilled water). The TBARS values were calculated from a standard curve $\left(\mathrm{R}^{2}=0.998\right)$ and expressed as mg malondialdehyde/ $\mathrm{kg}(\mathrm{mg} \mathrm{MA} / \mathrm{kg})$.

Texture analyses. Warner-Bratzler shear force (WBSF) was measured using a Texture Analyser (TA.HDPlus, Stable Microsystems Godalming, Surrey, UK) with WBS (TA-7) probe. 2-cm-thick steaks were cooked on an electric grill until a core temperature of $70^{\circ} \mathrm{C}$ was obtained. Both sides of steaks were cooked at once. The internal temperature was monitored by using thermocouples (Testo 175T2 Data logger, Germany). After cooking, steaks were overwrapped in polyvinyl chloride film and stored at $2^{\circ} \mathrm{C}$ for $24 \mathrm{~h}$. Ten cylindrical cores $(1.27 \mathrm{~cm}$ diameter) were obtained from each steak strip parallel to the muscle fibers using a mechanical coring device (2). Shear force was recorded as N.

Sensory analyses. Sliced meat samples (2-cm-thick) were stored at $-20^{\circ} \mathrm{C}$ in a vacuum pack until the analysis. Frozen samples were thawed for $24 \mathrm{~h}$ at $+4^{\circ} \mathrm{C}$. Steaks were grilled on an electric grill until they reached a core temperature of $70^{\circ} \mathrm{C}$ (2). After cooking, each steak was cut into $2 \times 2 \mathrm{~cm}$ squares with no edges, visible fat, or tendons, randomly codified with a three-digit-code, then wrapped in aluminum foil, and kept warm until the examination (in $15 \mathrm{~min}$ ). The panel was performed by six semi-trained panelists under controlled conditions. Panelists were selected from among the staff of the Department of Food Science and Technology (Faculty of Veterinary Medicine, University of Selçuk, Turkey). An orientation (for $30 \mathrm{~min}$ ) was given to the panelists about flavor, juiciness and tenderness of meat. A total of twenty sensory sessions were conducted with the same panelists. Samples were presented to the panelists randomly. They evaluated three treatments (D, B, V aging) twice at each session, so each panelist evaluated six samples at each session. Eating qualities such as flavor, juiciness, tenderness and overall likes were evaluated using an eight-point scale. Its score is indicated by 1 point $=$ dislike extremely to 8 point $=$ extremely. Water and unsalted bread were provided to cleanse the palate between samples.

Histological observation and sarcomere length. Muscle samples $\left(1 \mathrm{~cm}^{3}\right)$ were fixed in formalin solution $(10 \%)$ and 
processed by using routine histological techniques. Next, they were blocked with paraffin. Samples were stained with Crossman's triple staining method (8). Cross-sections were evaluated under a light microscope (Leica DM 250), and sarcomere lengths were measured.

Microbial analyses. Total viable count (TVC), total psychrophilic bacteria (PSY), Enterobacteriaceae, lactic acid bacteria (LAB), and yeast-mold populations were analyzed according to standard methods BAM-2001, ISO 17410-2001, ISO 21528-2-2017, ISO 1372-1995 and ISO 21527-1-2008, respectively. On the $0,7,14,21$, and 28 days, before weighing and trimming, $10 \mathrm{~g}$ of samples which would represent the whole sample were removed aseptically, placed into stomacher bags and stomached for 2 min with maximal recovery diluent (Merck 1.12535). Appropriate dilutions were plated in duplicate and enumerated after incubation on Plate Count Agar (Merck 1.12535; $37^{\circ} \mathrm{C}, 24 \mathrm{~h}$ for TVC; $7^{\circ} \mathrm{C} 240 \mathrm{~h}$ for PSY), Violed Red Bile Dextrose Agar (Merck $1.10275 ; 37^{\circ} \mathrm{C}, 24-48 \mathrm{~h}$ for Enterobacteriaceae), De Man, Rogosa and Sharpe Agar (Merck $1.10660 ; 28^{\circ} \mathrm{C}, 48 \mathrm{~h}$ for LAB), Dichloran Rose Bengal Chloramphenicol Agar (Merck $1.00466 ; 20^{\circ} \mathrm{C}$ for $120 \mathrm{~h}$ for yeast and mold).

Statistical analyses. All experimental data were evaluated according to One-Way ANOVA in the SPSS Version 21 for Windows software (SPSS Inc., Chicago, IL, USA). The treatment was designed as four replications. In the study, $\mathrm{pH}$, color, $\mathrm{a}_{\mathrm{w}}$, TBARS, WBSF, sarcomere length, and microbial analyses included fixed effect due to aging method $x$ aging days and random residual error. In the sensory analyses, sessions scores were recorded as 1 to 8 . Three replications of all measurements were taken from samples. These data were analyzed with One-Way ANOVA, using aging method $\times$ aging days as factors. Three aging methods $(\mathrm{D}, \mathrm{B}, \mathrm{V})$ and five aging times $(0,7$, 14, 21 and 28 days) were evaluated. Duncan multiple-comparison tests were applied to detect differences between groups. All data were tested for significance $(p<0.05)$ and results were reported in tables. Data were expressed as means plus standard error.

\section{Results and discussion}

Results of physicochemical properties of samples are given in Tab 1. pH is a major determinant of meat quality. The meat has high quality in the $\mathrm{pH}_{-}$range 5.4-5.6, and the quality of meat decreases at $\mathrm{pH}>5.8$ (39). According to our results $\mathrm{pH}$ values are ranged within 5.44 to 5.82 . Moreover, the aging methods had significant effects $(\mathrm{p}<0.05)$ on $\mathrm{pH}$. Samples from D and $\mathrm{B}$ aged for 28 days had slightly greater $\mathrm{pH}$ values $(\mathrm{p}<0.001)$ than those from $\mathrm{V}$ aged for 28 days $(5.82$ and 5.74 versus 5.65) similar to Dikeman et al. (10). On the other hand, no differences were found between $\mathrm{B}$ and $\mathrm{V}$ aging in $\mathrm{pH}$ by $\mathrm{Li}$ et al. (24). The $\mathrm{pH}$ results

Tab. 1. Physicochemical analyses results of the aged samples

\begin{tabular}{|c|c|c|c|c|c|c|c|}
\hline \multirow{2}{*}{ Trait } & & \multicolumn{5}{|c|}{ Aging Method $\times$ Treatment Days } & \multirow{2}{*}{$\mathbf{p}$} \\
\hline & & 0 & 7 & 14 & 21 & 28 & \\
\hline \multirow{4}{*}{ pH } & D & $5.55 \pm 0.02^{2 a}$ & $5.68 \pm 0.03^{\text {ya }}$ & $5.65 \pm 0.02^{\text {yab }}$ & $5.68 \pm 0.02^{\text {ya }}$ & $5.82 \pm 0.03^{\text {ха }}$ & *** \\
\hline & B & $5.44 \pm 0.03^{\text {th }}$ & $5.57 \pm 0.02^{2 b}$ & $5.67 \pm 0.03^{\text {xya }}$ & $5.65 \pm 0.01^{\text {yab }}$ & $5.74 \pm 0.03^{\times a}$ & *** \\
\hline & V & $5.56 \pm 0.04^{\mathrm{a}}$ & $5.60 \pm 0.02^{b}$ & $5.56 \pm 0.03^{c}$ & $5.61 \pm 0.02^{b}$ & $5.65 \pm 0.01^{b}$ & \\
\hline & $\mathbf{p}$ & ** & * & * & * & *** & \\
\hline \multirow{4}{*}{ TBARS, mg MA/kg } & D & $0.30 \pm 0.03^{y}$ & $0.38 \pm 0.05^{y}$ & $0.71 \pm 0.09 \times$ & $0.79 \pm 0.1^{\times a}$ & $0.85 \pm 0.05^{\text {хa }}$ & *** \\
\hline & B & $0.37 \pm 0.04^{z}$ & $0.41 \pm 0.05^{y z}$ & $0.53 \pm 0.05^{x y b}$ & $0.71 \pm 0.02^{\text {xya }}$ & $0.84 \pm 0.1^{\text {ха }}$ & *** \\
\hline & $\mathbf{V}$ & $0.31 \pm 0.07^{y}$ & $0.31 \pm 0.03^{y}$ & $0.45 \pm 0.04^{x y b}$ & $0.47 \pm 0.05^{x y b}$ & $0.54 \pm 0.06^{\times b}$ & ** \\
\hline & $p$ & & & * & ** & ** & \\
\hline \multirow{4}{*}{$a_{w}$} & D & $0.965 \pm 0.001$ & $0.964 \pm 0.002$ & $0.964 \pm 0.001$ & $0.964 \pm 0.001$ & $0.962 \pm 0.002$ & \\
\hline & B & $0.968 \pm 0.001^{x}$ & $0.967 \pm 0.001^{x y}$ & $0.967 \pm 0.002^{x y}$ & $0.963 \pm 0.001^{y z}$ & $0.960 \pm 0.002^{z}$ & $* *$ \\
\hline & V & $0.967 \pm 0.001$ & $0.969 \pm 0.001$ & $0.967 \pm 0.003$ & $0.966 \pm 0.001$ & $0.963 \pm 0.001$ & \\
\hline & $p$ & & & & & & \\
\hline \multirow{4}{*}{ Moisture,\% } & D & $74.63 \pm 0.42^{x}$ & $74.16 \pm 0.33^{\text {xyab }}$ & $73.09 \pm 0.37^{y z}$ & $72.38 \pm 0.39^{z a}$ & $72.63 \pm 0.55^{2}$ & ** \\
\hline & B & $74.58 \pm 0.31^{x}$ & $73.63 \pm 0.36^{x y b}$ & $72.43 \pm 0.96^{y}$ & $71.98 \pm 0.64^{y a}$ & $72.78 \pm 0.49 y$ & * \\
\hline & V & $74.56 \pm 0.24$ & $75.09 \pm 0.47^{a}$ & $73.78 \pm 0.42$ & $73.98 \pm 0.52^{b}$ & $72.85 \pm 1.21$ & \\
\hline & $p$ & & * & & * & & \\
\hline \multirow{4}{*}{ Weight Loss,\% } & D & - & $9.31 \pm 0.96^{\text {ya }}$ & $15.40 \pm 1.90^{\text {ya }}$ & $22.99 \pm 2.91^{\text {ха }}$ & $22.84 \pm 12.39 \times a$ & ** \\
\hline & B & - & $10.83 \pm 0.87^{\text {ya }}$ & $14.05 \pm 1.37^{\text {xya }}$ & $17.08 \pm 1.65^{\times a}$ & $17.33 \pm 1.36^{\text {хa }}$ & * \\
\hline & V & - & $0.023 \pm 0.023^{b}$ & $0.16 \pm 0.023^{b}$ & $0.40 \pm 0.033^{b}$ & $0.56 \pm 0.055^{b}$ & \\
\hline & $p$ & & $* * *$ & $* * *$ & $* * *$ & $* * *$ & \\
\hline \multirow{4}{*}{ WBSF, N } & D & $45.01 \pm 2.90^{x}$ & $39.39 \pm 2.81^{x y}$ & $38.92 \pm 1.65^{x y}$ & $37.81 \pm 1.50^{\text {ya }}$ & $37.32 \pm 2.17^{\text {ya }}$ & \\
\hline & B & $41.13 \pm 2.51^{x}$ & $38.73 \pm 1.34^{x}$ & $37.90 \pm 2.11^{x}$ & $36.97 \pm 1.73^{\text {xуa }}$ & $32.23 \pm 1.25^{\mathrm{yb}}$ & ** \\
\hline & $\mathbf{V}$ & $49.84 \pm 2.55^{x}$ & $38.20 \pm 2.16^{y}$ & $32.75 \pm 1.92^{\mathrm{yz}}$ & $32.04 \pm 1.47^{2 b}$ & $30.44 \pm 1.73^{2 b}$ & $* *$ \\
\hline & $p$ & & & & * & * & \\
\hline \multirow{4}{*}{$\begin{array}{l}\text { Sarcomere } \\
\text { Length, } \mu \mathrm{m}\end{array}$} & D & $1.74 \pm 0.05^{\times a}$ & $1.56 \pm 0.04^{y}$ & $1.62 \pm 0.03^{x y}$ & $1.69 \pm 0.03^{x y}$ & $1.63 \pm 0.04^{x y}$ & * \\
\hline & B & $1.55 \pm 0.04^{y b}$ & $1.67 \pm 0.03^{x y}$ & $1.67 \pm 0.03^{x y}$ & $1.61 \pm 0.04^{x y}$ & $1.70 \pm 0.03^{x}$ & * \\
\hline & V & $1.61 \pm 0.02^{\mathrm{ab}}$ & $1.60 \pm 0.03$ & $1.69 \pm 0.06$ & $1.63 \pm 0.06$ & $1.65 \pm 0.02$ & \\
\hline & $p$ & ** & & & & & \\
\hline
\end{tabular}

Explanations: D - dry aging; B - dry aging in a bag; $\mathrm{V}$ - wet aging in a vacuum shrink pack. TBARS - thiobarbituric acid reactive substances; WBSF - Warner-Bratzler shear force. ${ }^{\mathrm{x}-\mathrm{t}}$ Values within a row with different letters are significantly different $(p<0.05)$. ${ }^{a-c}$ Values within a column with different letters are significantly different $(\mathrm{p}<0.05) .{ }^{*} \mathrm{p}<0.05 ; * * \mathrm{p}<0.01 ; * * * \mathrm{p}<0.001$. 
of the present study showed that all samples were still acceptable at 28 days (39).

Meat undergoes undesirable changes during preservation at refrigeration temperatures. Chemical changes related to $\mathrm{pH}$ and lipid oxidation have a major effect on decreasing the quality, palatability and texture of the meat (27). In the present study, TBARS values were increased in all groups (ranging from 0.30 to $0.85 \mathrm{mg}$ / MA kg) during the aging period. There were significant differences among the groups at $14^{\text {th }}, 21^{\text {st }}$ and $28^{\text {th }}$ days $(\mathrm{p}<0.01 ; \mathrm{p}<0.001)$. V samples had the lowest TBARS values in comparison to $D$ and $B$ samples at the $28^{\text {th }}$ days. $\mathrm{D}$ and $\mathrm{B}$ samples had the highest TBARS values from the beginning of the $21^{\text {st }}$ day. According to TBARS values in the current study, all samples still maintained their consumability $(<1.0 \mathrm{mg} / \mathrm{MA} \mathrm{kg})$ in $28^{\text {th }}$ days $(32,36)$.

During the aging process, trim and weight loss in meat increase due to the water that is excreted (15). In this study, aging application resulted in a significant decrease in moisture content of D and B samples. D samples resulted in greater weight loss than B. Also, $\mathrm{V}$ aged loins had less weight loss at the $28^{\text {th }}$ day in comparison with both $\mathrm{D}$ and $\mathrm{B}$ aging $(0.56 \%$ versus $22.84 \%$ and $17.33 \%$, respectively). This finding is in accordance with the results of Dikeman et al. (10), who reported higher weight loss with $\mathrm{D}$ aging when compared with $\mathrm{B}$ and $\mathrm{V}$ aging. The difference in weight loss between $\mathrm{D}$ and $\mathrm{B}$ aging carries critical economic results, although it has no significance $(p>0.05)$. Similarly, DeGeer et al. (9) and Ahnström et al. (1) reported that $\mathrm{B}$ aging significantly reduced weight losses in comparison with $\mathrm{D}$ aging. Moreover, aging methods had no effects $(p>0.05)$ on $a_{w}$ during the aging periods.

Data for changes in the color of the samples are given in Tab 2. pH changes and lipid peroxidation have an effect on flavor, color and texture of the meat (29). Also, it was stated that $\mathrm{a}^{*}$ is the most sensitive value to changes in the red color of the meat (5). According to our results, aging methods had no significant effects $(p>0.05)$ on $\mathrm{L}^{*}$ and $\mathrm{a}^{*}$ values on the $28^{\text {th }}$ day, except $\mathrm{b}^{*}(\mathrm{p}<0.05)$. Similarly, Li et al. (24) stated that there were no significant differences between $\mathrm{V}$ and $\mathrm{B}$ aged samples on the $14^{\text {th }}$ day. $L^{*}, a^{*}$ and $b^{*}$ values of $B$ aged samples were significant during the aging period $(\mathrm{p}<0.05 ; \mathrm{p}<0.001)$.

Results of WBSF analyses of samples are given in Tab 1. The ultimate $\mathrm{pH}$ value influences the meat texture significantly. It is known that the meat at intermediate $\mathrm{pH}$ values $(<5.8)$ has the lowest tenderization degree and it has maximum shear force values in a range from pH 5.8 to 6.3 (33). WBSF values of the present study are ranged within $41.13 \pm 2.90$ to $30.44 \pm 1.73$. Aging method had a significant effect on WBSF at the $21^{\text {st }}$ and $28^{\text {th }}$ days $(\mathrm{p}<0.05)$. In our study, $\mathrm{D}$ aging on the $28^{\text {th }}$ day had greater WBSF values than $\mathrm{B}$ and $\mathrm{V}$ aging $(p<0.05)$. Similarly, Laster et al. (23) reported higher

Tab. 2. Color and sensory evaluation results of aged samples

\begin{tabular}{|c|c|c|c|c|c|c|c|}
\hline \multirow{2}{*}{ Factor } & & \multicolumn{5}{|c|}{ Aging Method $\times$ Treatment Days } & \multirow{2}{*}{$p$} \\
\hline & & 0 & 7 & 14 & 21 & 28 & \\
\hline \multirow{4}{*}{$L^{*}$} & D & $35.84 \pm 1.03^{b}$ & $36.68 \pm 1.03$ & $36.62 \pm 0.73$ & $37.16 \pm 0.97^{b}$ & $37.32 \pm 0.46$ & \\
\hline & B & $40.14 \pm 0.36^{\times a}$ & $40.37 \pm 0.78^{x}$ & $38.66 \pm 0.49^{x y}$ & $37.65 \pm 0.55^{y b}$ & $39.49 \pm 1.04^{x y}$ & * \\
\hline & $\mathbf{V}$ & $37.72 \pm 1.68^{\mathrm{ab}}$ & $39.38 \pm 1.56$ & $38.32 \pm 1.05$ & $41.16 \pm 1.17^{a}$ & $39.77 \pm 1.06$ & \\
\hline & $p$ & * & & & ** & & \\
\hline \multirow{4}{*}{$a^{*}$} & D & $17.91 \pm 0.75$ & $17.96 \pm 0.58$ & $19.18 \pm 0.53^{a}$ & $18.15 \pm 0.44$ & $18.19 \pm 0.40$ & \\
\hline & B & $20.24 \pm 0.65^{x}$ & $17.00 \pm 0.52^{y}$ & $16.96 \pm 0.58^{y b}$ & $16.93 \pm 0.51^{y}$ & $16.88 \pm 0.60^{y}$ & * * \\
\hline & $\mathbf{V}$ & $18.83 \pm 0.81^{a}$ & $18.25 \pm 0.49$ & $17.49 \pm 0.28^{b}$ & $18.30 \pm 0.55$ & $18.61 \pm 0.60$ & \\
\hline & $p$ & & & ** & & & \\
\hline \multirow{4}{*}{$\mathbf{b}^{*}$} & D & $7.23 \pm 0.79^{b}$ & $6.72 \pm 0.44$ & $7.74 \pm 0.44^{\mathrm{a}}$ & $8.06 \pm 0.42$ & $6.87 \pm 0.27^{b}$ & \\
\hline & B & $11.28 \pm 0.60^{x a}$ & $7.40 \pm 0.43^{y}$ & $6.54 \pm 0.28^{y b}$ & $7.77 \pm 0.35^{y}$ & $7.87 \pm 0.47^{\text {yab }}$ & ** \\
\hline & V & $9.02 \pm 1.09^{\mathrm{ab}}$ & $8.24 \pm 0.54$ & $7.77 \pm 0.32^{\mathrm{a}}$ & $7.69 \pm 0.32$ & $8.68 \pm 0.39^{a}$ & \\
\hline & $p$ & ** & & * & & ** & \\
\hline \multirow{4}{*}{ Flavour } & D & $4.83 \pm 0.41$ & $5.33 \pm 0.33^{b}$ & $5.83 \pm 0.32^{b}$ & $5.75 \pm 0.31$ & $5.92 \pm 0.31$ & \\
\hline & B & $5.50 \pm 0.35$ & $5.58 \pm 0.2 g^{b}$ & $5.17 \pm 0.27^{b}$ & $5.42 \pm 0.36$ & $5.75 \pm 0.39$ & \\
\hline & V & $5.50 \pm 0.31^{y}$ & $6.17 \pm 0.24^{\text {хуа }}$ & $6.75 \pm 0.35^{\text {ха }}$ & $5.83 \pm 0.35^{y}$ & $5.58 \pm 0.26^{y}$ & * \\
\hline & $p$ & & & ** & & & \\
\hline \multirow{4}{*}{ Juiciness } & D & $4.67 \pm 0.28$ & $4.50 \pm 0.36^{b}$ & $4.75 \pm 0.37^{\mathrm{b}}$ & $5.17 \pm 0.32$ & $4.92 \pm 0.40$ & \\
\hline & B & $4.92 \pm 0.43$ & $4.50 \pm 0.36^{b}$ & $4.10 \pm 0.42^{b}$ & $4.50 \pm 0.50$ & $5.00 \pm 0.43$ & \\
\hline & V & $4.42 \pm 0.34^{y}$ & $5.67 \pm 0.33^{\text {ха }}$ & $6.00 \pm 0.43^{x a}$ & $5.50 \pm 0.23^{y}$ & $4.50 \pm 0.34^{y}$ & $* *$ \\
\hline & $p$ & & * & * & & & \\
\hline \multirow{4}{*}{ Tenderness } & D & $3.50 \pm 0.36^{2 b}$ & $4.08 \pm 0.40^{y z b}$ & $4.92 \pm 0.38^{x y b}$ & $5.33 \pm 0.40^{x}$ & $5.42 \pm 0.38^{x}$ & * \\
\hline & B & $5.17 \pm 0.46^{a}$ & $5.08 \pm 0.36^{a b}$ & $4.80 \pm 0.39^{b}$ & $5.00 \pm 0.43$ & $5.42 \pm 0.40$ & \\
\hline & $\mathbf{v}$ & $4.25 \pm 0.48^{\text {yab }}$ & $5.58 \pm 0.34^{\text {хa }}$ & $6.17 \pm 0.39 \times$ & $5.25 \pm 0.35^{x y}$ & $5.42 \pm 0.45^{x y}$ & * \\
\hline & $p$ & * & * & * & & & \\
\hline \multirow{4}{*}{ Overall like } & D & $4.83 \pm 0.42$ & $5.33 \pm 0.40^{b}$ & $5.75 \pm 0.35^{b}$ & $5.75 \pm 0.33$ & $5.92 \pm 0.31$ & \\
\hline & B & $6.08 \pm 0.35$ & $5.42 \pm 0.2 g^{b}$ & $5.00 \pm 0.33^{b}$ & $5.67 \pm 0.41$ & $6.17 \pm 0.38$ & \\
\hline & V & $5.17 \pm 0.47^{2}$ & $6.50 \pm 0.26^{\text {xya }}$ & $6.75 \pm 0.31^{\text {хa }}$ & $5.58 \pm 0.40^{y z}$ & $5.75 \pm 0.33^{x y z}$ & * \\
\hline & $p$ & & * & ** & & & \\
\hline
\end{tabular}

Explanations: D - dry aging, B - dry aging in a bag, $\mathrm{V}$ - wet aging in a vacuum shrink pack. ${ }^{\mathrm{x}-\mathrm{z}}$ Values within a row with different letters are significantly different $(p<0.05)$. ${ }^{a-c}$ Values within a column with different letters are significantly different $(\mathrm{p}<0.05){ }^{*} \mathrm{p}<0.05 ; * * \mathrm{p}<0.01 ; * * * \mathrm{p}<0.001$ 
WBSF in $\mathrm{D}$ aging in comparison with $\mathrm{V}$ aging. However, Oreskovich et al. (26) and Parrish et al. (28) found no effects of V and D aging, and Ahnström et al. (1) and DeGeer et al. (9) also found no effects of D and B aging on WBSF. Moreover, Sitz et al. (34), Smith et al. (35) and $\mathrm{Li}$ et al. (24) reported no differences in WBSF between $\mathrm{B}$ and $\mathrm{V}$ aging. According to the results of the current study, WBSF values were influenced by the ultimate $\mathrm{pH}$ values of the samples. These results confirm the previous studies of Pipek et al. (30).

Results of sensory evaluation of the samples are given in Tab 2. On the $14^{\text {th }}$ day of the aging, the scores given for the flavor values of the $\mathrm{V}$ samples were higher than those of the D and B, and the differences were significant $(\mathrm{p}<0.01)$. On the $21^{\text {st }}$ and $28^{\text {th }}$ days, the differences between the groups were not significant $(p>0.05)$. However, V samples had the highest sensory scores of flavor, juiciness, tenderness and overall, like they did at the $14^{\text {th }}$ day $(6.75 \pm 0.35,6.0 \pm 0.43,6.17 \pm 0.39$ and $6.75 \pm 0.31$, respectively). In general, these results agree with those of Parrish et al. (28) and Sitz et al. (34).

Tab. 1 shows the results of the sarcomere length of the samples. Sarcomere length is closely related to the $\mathrm{pH}$ and denaturation of myosin heads (31). Offer (25) states that about $50 \%$ of myosin heads are denatured during rigor mortis, depending on the rate of $\mathrm{pH}$ fall, chilling rate and glycolysis rate in the muscle. Hughes period. Moreover, Hughes et al. (14) argued that the denaturation of myosin heads, and sarcomere length are dependent on $\mathrm{pH}$, temperature and degree of glycolysis in the muscle during early rigor development.

Results of the microbiological properties of the samples are given in Tab. 3. The limits in EU Regulation No. 2073/2005 state that $5 \log \mathrm{CFU} / \mathrm{g}$ is an acceptable limit for beef carcasses for TVC. In our study, initial beef samples of D, B and V had an acceptable microbiological quality with TVC $(4.68 \pm 0.39,4.34 \pm 0.11,4.35 \pm$ $0.21 \log \mathrm{CFU} / \mathrm{g}$, respectively), and Enterobacteriaceae $(2.36 \pm 0.28,1.76 \pm 0.21$ and $2.33 \pm 0.28 \log \mathrm{CFU} / \mathrm{g}$, respectively). After the aging process, there was a significant difference $(p<0.05)$ among the treatments for TVC, Enterobacteriaceae and yeast-mold. Increasing the aging period increased TVC, PSY, and LAB in both $\mathrm{B}$ and $\mathrm{V}$ samples, increased Enterobacteriaceae in V and increased yeast-mold in B samples $(p<0.05)$. In several studies an increase was observed in TVC at the 21 days of aging $(12,24)$. V samples had more TVC and less yeast-mold in comparison with $\mathrm{D}$ and $\mathrm{B}$ samples $(p<0.0001)$ after 14 days. The LAB counts were higher in $B$ and $V$ than $D$ samples. These higher $L A B$ values can be explained by the microaerophilic conditions in packaged meats (28). Also, greater yeast-mold counts on D samples probably occurred as a result of direct contact with atmospheric conditions during aging. A lack et al. (14) reported that denaturation of the myosin heads with falling $\mathrm{pH}$ provides a shrinkage force. In our study, a narrow range of sarcomere lengths was found among samples. In the beginning, the differences in the sarcomere lengths of the samples were found significant $(\mathrm{p}<0.01)$, on the following days they were not $(\mathrm{p}>0.05)$. There were no significant effects of aging treatment on sarcomere length on the $28^{\text {th }}$ day $(\mathrm{p}>0.05)$. This result is in accordance with Battaglia et al., (3) who found no significant changes $(p>0.05)$ in the sarcomere length of $21^{\text {st }}$ day $\mathrm{V}$ aged samples. Therefore, the differences between the groups at the $0^{\text {th }}$ day probably related to $\mathrm{pH}$, and glycolysis level of the muscles before rigor mortis
Tab. 3. Microbiological results of aged samples $(\log \mathrm{CFU} / \mathrm{g})$

\begin{tabular}{|c|c|c|c|c|c|c|c|}
\hline \multirow{2}{*}{ Factor } & & \multicolumn{5}{|c|}{ Aging Method × Treatment Days } & \multirow{2}{*}{$\mathbf{p}$} \\
\hline & & 0 & 7 & 14 & 21 & 28 & \\
\hline \multirow[t]{4}{*}{ TVC } & D & $4.68 \pm 0.39$ & $5.03 \pm 0.36$ & $4.93 \pm 0.33^{b}$ & $5.36 \pm 0.31^{b}$ & $5.44 \pm 0.44^{b}$ & \\
\hline & B & $4.34 \pm 0.11^{y}$ & $4.52 \pm 0.23^{y}$ & $5.58 \pm 0.17^{x b}$ & $5.72 \pm 0.29^{\times b}$ & $5.74 \pm 0.18^{\times b}$ & $* * *$ \\
\hline & $\mathbf{V}$ & $4.35 \pm 0.21^{y}$ & $5.08 \pm 0.47^{y}$ & $6.20 \pm 0.10^{\text {ха }}$ & $6.55 \pm 0.12^{\mathrm{xa}}$ & $6.70 \pm 0.26^{\text {хa }}$ & $* * *$ \\
\hline & $\mathbf{p}$ & & & $* * *$ & $* * *$ & ** & \\
\hline \multirow[t]{4}{*}{ PSY } & D & $5.34 \pm 0.36$ & $6.23 \pm 0.52$ & $6.77 \pm 0.52$ & $7.45 \pm 0.52$ & $7.47 \pm 0.69$ & \\
\hline & B & $5.09 \pm 0.30^{2}$ & $6.00 \pm 0.28^{y}$ & $7.37 \pm 0.43^{x}$ & $8.12 \pm 0.21^{x}$ & $8.20 \pm 0.24^{x}$ & $* * *$ \\
\hline & $\mathbf{V}$ & $5.20 \pm 0.39 y$ & $5.53 \pm 0.63^{y}$ & $7.08 \pm 0.18^{x}$ & $7.46 \pm 0.11^{x}$ & $7.64 \pm 0.22^{x}$ & $* * *$ \\
\hline & $\mathbf{p}$ & & & & & & \\
\hline \multirow[t]{4}{*}{ Enterobacteriaceae } & D & $2.36 \pm 0.28$ & $2.35 \pm 0.46$ & $2.73 \pm 0.36$ & $3.81 \pm 0.34^{\mathrm{ab}}$ & $3.31 \pm 0.57^{\mathrm{ab}}$ & \\
\hline & B & $1.76 \pm 0.21$ & $2.57 \pm 0.43$ & $3.46 \pm 0.41$ & $2.91 \pm 0.52^{b}$ & $2.04 \pm 0.60^{\mathrm{b}}$ & \\
\hline & V & $2.33 \pm 0.28^{y}$ & $2.88 \pm 0.60^{y}$ & $3.54 \pm 0.27 x y$ & $4.48 \pm 0.20^{\text {хa }}$ & $4.53 \pm 0.52^{\text {хa }}$ & $* * *$ \\
\hline & $p$ & & & & * & * & \\
\hline \multirow[t]{4}{*}{ LAB } & D & $5.79 \pm 0.37^{a}$ & $4.86 \pm 0.46$ & $5.22 \pm 0.36^{b}$ & $5.65 \pm 0.40^{b}$ & $6.50 \pm 1.19$ & \\
\hline & B & $4.51 \pm 0.24^{2 b}$ & $4.73 \pm 0.35^{2}$ & $5.53 \pm 0.24^{\text {ab }}$ & $6.03 \pm 0.16^{x y b}$ & $6.66 \pm 0.18^{x}$ & $* * *$ \\
\hline & V & $4.52 \pm 0.2 g^{y b}$ & $5.19 \pm 0.57^{y}$ & $6.27 \pm 0.11^{x a}$ & $6.88 \pm 0.19^{x a}$ & $6.86 \pm 0.30^{x}$ & $* * *$ \\
\hline & $\mathbf{p}$ & * & & * & * & & \\
\hline \multirow[t]{4}{*}{ Yeast-Mold } & D & $3.99 \pm 0.31$ & $4.54 \pm 0.45$ & $4.85 \pm 0.40^{a}$ & $5.33 \pm 0.43^{a}$ & $5.24 \pm 0.77^{\mathrm{ab}}$ & \\
\hline & B & $3.46 \pm 0.10^{2}$ & $3.77 \pm 0.62^{2}$ & $5.25 \pm 0.22^{\text {ya }}$ & $5.87 \pm 0.24^{\text {xya }}$ & $6.45 \pm 0.11^{\text {ха }}$ & $* * *$ \\
\hline & V & $3.17 \pm 0.27$ & $3.44 \pm 0.52$ & $3.22 \pm 0.24^{b}$ & $3.32 \pm 0.24^{b}$ & $3.95 \pm 0.46^{\mathrm{b}}$ & \\
\hline & $p$ & & & $* * *$ & $* * *$ & * & \\
\hline
\end{tabular}

Explanations: D - dry aging; B - dry aging in a bag; V - wet aging in a vacuum shrink pack. TVC Total viable count; PSY - Total psychrophilic bacteria; LAB - Lactic acid bacteria. ${ }^{\mathrm{x}-\mathrm{z}}$ Values within a row with different letters are significantly different $(\mathrm{p}<0.05)$. ${ }^{\mathrm{a}-\mathrm{c}}$ Values within a column with different letters are significantly different $(\mathrm{p}<0.05)$. ${ }^{*} \mathrm{p}<0.05 ; * * \mathrm{p}<0.01 ; * * * \mathrm{p}<0.001$ 
of bacterial increase during the $\mathrm{D}$ aging probably occurred as a result of surface drying, as the water content decreased significantly (1).

The present study showed that the aging methods had significant effects on $\mathrm{pH}$, TBARS, weight loss and WBSF. All samples still maintained their consumability at 28 days according to $\mathrm{pH}$ and TBARS values. A greater weight loss was observed in D aging than $\mathrm{B}$ aging. It can be concluded that the differences of weight loss between D and B aging carries critical economic results, although it is not statistically significant. Thus, $\mathrm{B}$ aging has provided yield advantage according to the traditional $\mathrm{D}$ aging, and the wastage can be reduced in a controlled environment through the B aging method without negative effects on the meat quality. V aging with vacuum shrink packs provided the lowest shear force values in the aging period. Moreover, V aged samples had the highest sensory scores of flavor, juiciness, tenderness and overall like. The vacuum shrink pack, which can be successfully used in the wet aging method, and improved both textural and sensory characteristics of the meat significantly. Taken together, the use of the vacuum shrink pack is considered to be an alternative packing material in the wet aging method to improve the physicochemical and sensory quality of meat. Further studies are needed to obtain the desired properties and to shorten the aging time of aged meat.

\section{References}

1. Ahnström M. L., Seyfert M., Hunt M. C., Johnson D. E.: Dry aging of beef in a bag highly permeable to water vapour. Meat Sci. 2006, 73, 4, 674-679, doi 10.1016/j.meatsci.2006.03.006

2. AMSA, American Meat Science Association: Research guidelines for cookery, sensory evaluation and instrumental tenderness measurements of meat. Chicago, IL, USA 2015.

3. Battaglia C. T., Vilella G. F., Sousa B. I., Gomes C. L., de Felicio P. E., Pflanzer $S$. $B$.: Are sarcomere length and miofibrilar fragmentation index predictors for sensory and instrumental tenderness of aged beef? Meat Sci. 2016, 112, 148 , doi: 10.1016/j.meatsci.2015.08.105

4. Belew J. B., Brooks J. C., McKenna D. R., Savell J. W.: Warner-Bratzler shear evaluations of 40 bovine muscles. Meat Sci. 2003, 64, 4, 507-512, doi: 10.1016/ S0309-1740(02)00242-5

5. Brewer M. S., Rostogi B. K., Argoudelis L., Sprouls G. R.: Sodium lactate/sodium chloride effects on aerobic plate counts and color of aerobically packaged ground pork. J. Food Sci. 1995, 60, 58-62.

6. Campbell R. E., Hunt M. C., Levis P., Chambers E.: Dry-aging effects on palatability of beef longissimus muscle. Food Chem. Toxicol. 2001, 66, 2, 196-199.

7. CIE: Technical Report: Colorimetry 2004, doi: ISBN 3901906339

8. Culling C. F. A., Allison R. T., Barr W. T.: Cytology technique, [in:] Cellular Pathology Technique. Butterworths \& Co. Ltd, London 1985, doi: 10.1016 B978-0-407-72903-2.50031-9

9. DeGeer S. L., Hunt M. C., Bratcher C. L., Crozier-Dodson B. A., Johnson D. E., Stika J. F.: Effects of dry aging of bone-in and boneless strip loins using two aging processes for two aging times. Meat Sci. 2009, 83, 4, 768-774, doi: 10.1016/j.meatsci.2009.08.017

10. Dikeman M. E., Obuz E., GökV., Akkaya L., Stroda S.: Effects of dry, vacuum, special bag aging; USDA quality grade; and end-point temperature on yields and eating quality of beef Longissimus lumborum steaks. Meat Sci. 2013, 94, 2, 228-233, doi: 10.1016/j.meatsci.2013.02.002

11. EC (European Community): Commission regulation (EC) No. 2073/2005. Microbiological criteria for foodstuffs. Official Journal 2005, 338, 1, 22.12.2005.

12. Gudjónsdóttir M., Gacutan M. D., Mendes A. C., Chronakis I. S., Jespersen L., Karlsson A. H.: Effects of electrospun chitosan wrapping for dry aging of beef as studied by microbiological, physicochemical and low-field nuclear magnetic resonance analysis. Food Chem. 2015, 184, 167-175.

13. Huff-Lonergan E., Lonergan S. M.: Mechanisms of water-holding capacity of meat: The role of postmortem biochemical and structural changes. Meat Sci. 2005, 71, 194-204, doi: 10.1016/j.meatsci.2005.04.022
14. Hughes J. M., Oiseth S. K., Purslow P. P., Warner R. D.: A structural approach to understanding the interactions between colour, water-holding capacity and tenderness. Meat Sci. 2014, 98, 520-532, doi: 10.1016/j.meatsci.2014.05.022

15. Jayasooriya S. D., Torley P. J., D'Arcy B. R., Bhandari B. R.: Effect of high power ultrasound and ageing on the physical properties of bovine Semitendinosus and Longissimus muscles. Meat Sci. 2007, 75, 628-639.

16. Jelenikova J., Pipek P., Staruch L.: The influence of ante-mortem treatment on relationship between $\mathrm{pH}$ and tenderness of beef. Meat Sci. 2008, 80, 3, 870-874, doi: 10.1016/j.meatsci.2008.04.004

17. Kahraman H. A., Gurbuz U.: Aging applications on beef meat. Manas J. Engineering 2018, 6, 1, 7-13

18. Kemp C. M., Sensky P. L., Bardsley R. G., Buttery P. J., Parr T.: Tenderness? An enzymatic view. Meat Sci. 2010, 84, 2, 248-256, doi: 10.1016/j.meatsci. 2009.06.008

19. Khan M. I., Jung S., Nam K. C., Jo C.: Postmortem Aging of Beef with Special Reference to the Dry Aging. Korean J. Food Sci. Anim. Resour. 2016, 36, 2 , 159-169, doi: 10.5851/kosfa.2016.36.2.159

20. Kim Y. H. B., Warner R. D., Rosenvold K.: Influence of high pre-rigor temperature and fast $\mathrm{pH}$ fall on muscle proteins and meat quality: a review. Anim. Prod. Sci. 2014, 54, 4, 375, doi: 10.1071/AN13329

21. Koohmaraie M., Geesink G. H.: Contribution of postmortem muscle biochemistry to the delivery of consistent meat quality with particular focus on the calpain system. Meat Sci. 2006, 74, 1, 34-43, doi: 10.1016/j.meatsci.2006.04.025

22. Kristensen L., Purslow P. P: The effect of ageing on the water-holding capacity of pork: role of cytoskeletal proteins. Meat Sci. 2001, 58, 1, 17-23, doi: 10.1016/ S0309-1740(00)00125-X

23. Laster M. A. Smith R. D., Nicholson K. L., Nicholson J. D. W. Miller R. K. Griffin D. B., Harris K. B., Savell J.W.: Dry versus wet aging of beef: Retail cutting yields and consumer sensory attribute evaluations of steaks from ribeyes, strip loins, top sirloins from two quality grade groups. Meat Sci. 2008, 80, 795-804, doi: 10.1016/j.meatsci.2008.03.024

24. Li X., Babol J., Wallby A., Lundström K.: Meat quality, microbiological status and consumer preference of beef gluteus medius aged in a dry ageing bag or vacuum. Meat Sci. 2013, 95, 2, 229-234, doi: 10.1016/j.meatsci.2013.05.009

25. Offer $G$.: Modelling of the formation of pale, soft and exudative meat: Effects of chilling regime and rate and extent of glycolysis. Meat Sci. 1991, 30, 2, 157-184, doi: 10.1016/0309-1740(91)90005-B

26. Oreskovich D. C., McKeith F. K., Carr T. R., Novakofski J., Bechtel P. J.: Effects of different aging procedures on the palatability of beef. J. Food Qual. 1988, 11, 151-158, doi: 10.1111/j.1745-4557.1988.tb00875.x

27. Park S. Y., Yoo S. S., Eun J. B., Lee H. C., Kim Y. J., Chin K. B.: Evaluation of lipid oxidation and oxidative products as affected by pork meat cut, packaging method, storage time during frozen storage $\left(-10^{\circ} \mathrm{C}\right)$. J. Food Sci. 2007, 72, C114-C119.

28. Parrish F. C., Boles J. A., Rust R. E., Olson D. G.: Dry and wet aging effects on palatability attributes of beef loin and rib steaks from three quality grades. J. Food Sci. 1991, 56, 601-603, doi: 10.1111/j.1365-2621.1991.tb05338.x

29. Pearson A. M., Gray J. I., Wolzak A. M., Horenstein N. A.: Safety implications of oxidized lipids in muscle food. Food Technol. 1983, 37, 121-129.

30. Pipek P., Haberl A., Jeleniková J.: Influence of slaughterhouse handling on the quality of beef carcasses. Czech J. Anim. Sci. 2003, 48, 371-378.

31. Purchas $R$. W: An assessment of the role of $\mathrm{pH}$ differences in determining the relative tenderness of meat from bulls and steers. Meat Sci. 1990, 27, 2, 129-140, doi: 10.1016/0309-1740(90)90061-A

32. Rahman M. H., Hossain M. M.,. Rahman S. M. E., Amin M. R., Oh D. H. Evaluation of physicochemical deterioration and lipid oxidation of beef muscle affected by freeze-thaw cycles. Korean J. Food Sci. An. 2015, 35, 772-782.

33. Silva J. A.: Influence of ultimate $\mathrm{pH}$ on bovine meat tenderness during ageing. Meat Sci.1999, 52, 453-459.

34. Sitz B. M., Calkins C. R., Feuz D. M., Umberger W. J., Eskridge K. M.: Consumer sensory acceptance and value of wet-aged and dry-aged beef steaks. J. Anim. Sci. 2006, 84, 1221-1226, doi:/2005.83122863x

35. Smith R. D., Nicholson K. L., Nicholson J. D. W. Harris K. B., Miller R. K. Griffin D. B., Savell J. W. Dry versus wet aging of beef: Retail cutting yields and consumer palatability evaluations of steaks from US Choice and US Select short loins. Meat Sci. 2008, 79, 631-639, doi: 10.1016/j.meatsci.2007.10.028

36. Tan W., Shelef L. A.: Effect of sodium chloride and lactates on chemical and microbial changes in refrigerated and frozen fresh ground pork. Meat Sci. 2002 , 62, 27-32.

37. Tarladgis B. G., Watts B. M., Younathan M. T., Dugan L.: A distillation method for the quantitative determination of malonaldehyde in rancid foods. J. Am. Oil Chem. Soc. 1960, 37, 44-48, doi: 10.1007/BF02630824

38. Warren K. E., Kastner C. L.: A comparison of dry-aged and vacuum-aged beef strip loins. J. Muscle Foods. 1992, 3, 2, 151-157, doi: 10.1111/j.1745-4573.1992. tb00471.x

39. Weglarz A.: Meat quality defined based on $\mathrm{pH}$ and colour depending on cattle category and slaughter season. Czech J. Anim. Sci. 2010, 55, 548-556.

Corresponding author: Hatice Ahu Kahraman Ph.D., Mehmet Akif Ersoy University, Faculty of Veterinary Medicine, Department of Food Hygiene and Technology, 15030, Burdur/Turkey; e-mail: h.ahuerdem@mehmetakif.edu.tr 